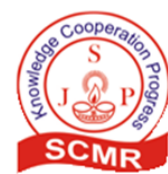

\title{
Modeling of Full Vehicle to Evaluate the Impact of Electric Powertrain on Steering Performance
}

\author{
Poornima R. Bodke*, Subim .N. Khan ${ }^{\#}$, Shoaib Iqbal ${ }^{\$}$, Aravind S. ${ }^{\circledR}$ \\ *,\#Department of Mechanical Engineering, RSCOE, Pune, India

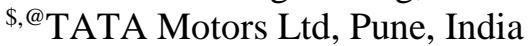

(Received 16 June 2020, accepted 20 October 2020)

https://doi.org/10.36224/ijes.130305

\begin{abstract}
The study of dynamic behavior of Electric Power Steering System (EPAS) is very critical to understand the overall handling of the vehicle. The appropriate feedback from the steering to the driver is crucial so that the driver get the precise steering feel in order to control the vehicle with ease during all kinds of maneuvers. For a maximum tire life, the steering system should maintain, a proper tire road contact, and proper tire geometry with respect to the chassis both during cornering and straight-ahead driving. The driver should be able to turn the vehicle with ease during low as well as high speed maneuver. A complete steering system dynamic model is developed and is integrated with the full vehicle model using AMESIM 1D simulation platform. The simulation is carried out as per the guidelines laid by the ISO 7401 standard criterion. In this project we have performed the simulation on three different vehicle models in which a behavioral comparison of EPAS between their Conventional \& Electric variants is performed. A thorough implementation of various vehicle SPMM parameters and $\mathrm{KnC}$ files is done in AMESim simulation model. Finally a list of Performance Aggregate Target Parameters is calculated. The resulting PAT parameter values are then compared with the test data and an appropriate design modification has been suggested accordingly.
\end{abstract}

Keywords: EPAS, Cornering Behavior, AMESim-1D, ISO7401, KnC, SPMM and PAT

\section{Introduction}

There are different EPAS systems available, which are used according to the vehicle's boundary conditions and the vehicle manufacturers' technological philosophy. In spite of their different designs, they all share similar functional requirements. EPAS system ensures safe operation in all driving situations. It provides highly dynamic response characteristics in the most varied driving situations. It also ensures sufficient level of steering assist for the driver in the case of intensive actuation force requirements. Minimal noise during all steering maneuvers and high quality steering characteristics in line with the philosophy of the vehicle brand are it's forte. The dynamic behavior of a road vehicle is a very critical aspect of active vehicle safety. The primary objective of ISO 7401 tests is to determine the transient response behavior of a vehicle. In this method, the characteristic values and functions in the time domains are considered necessary for characterizing vehicle transient responses. Test methods such as sinusoidal input (one period) of time domain are conducted based on strict steering wheel maneuvers. The time histories of variables used for data evaluation are plotted and then related characteristic values are calculated from fitting curves. 


\section{Literature review}

\subsection{AMESim Vehicle Model}

One-dimensional Computer-Aided Engineering (1D CAE), is an approach to modeling and analyzing multi-domain systems, and thus predicting their multidisciplinary performance, by integrating together validated analytical modeling blocks of electrical, hydraulic, pneumatic and mechanical subsystems into a comprehensive and schematic full-system model. It helps to create a concept design of complex mechatronic systems and analyze their transient and steady-state behavior.

1. Chassis Module

2. Tire \& Road Adherence Module

3. Suspension Module

4. Steering System Module

5. Sensor Module

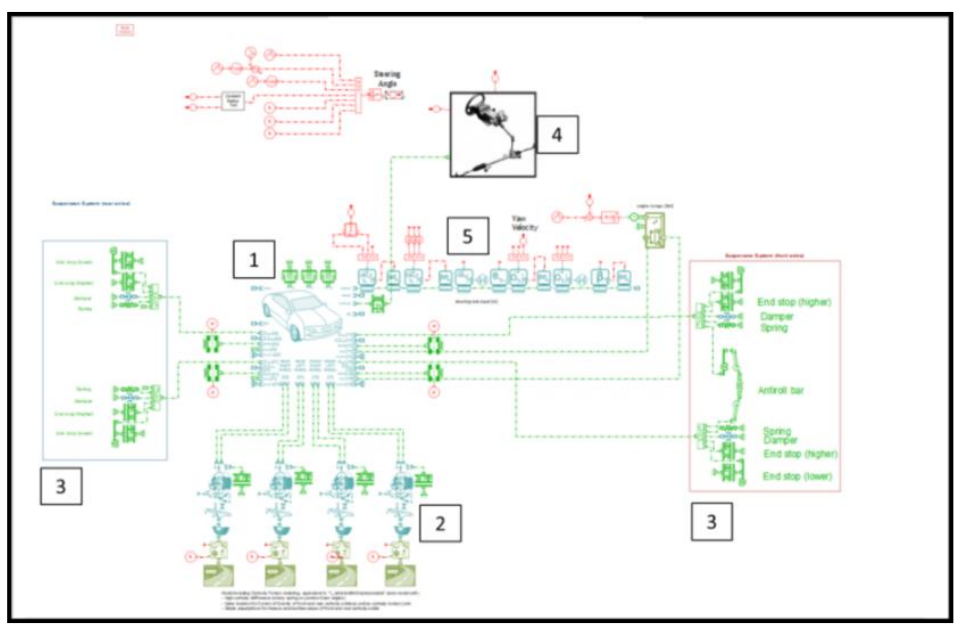

Figure 1: AMESim Vehicle Model

\subsubsection{Chassis Module}

The number of degrees of freedom of the system depends on the number of bodies and the nature of joints used for kinematic constraints. The chassis model is the central module for vehicle dynamics modeling to which all car sub-modules can be connected.The $18 \mathrm{DOF}$ chassis model is a multibody system containing several pieces, front carbody solid, rear carbody solid, steering rack, spindle, wheel and all the mechanical joints between these elements.The inputs to the chassis module are the 20 Kinematic \& Compliance files generated through K\&C Designer APP for the Front Left(11), Front Right(12), Rear Left(21) \& Rear Right(22) wheels.

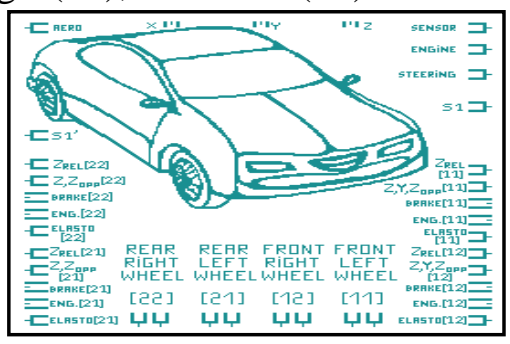

Figure 2: Chassis Module 


\subsubsection{Tire \& Road Adherence Module}

\subsubsection{Tire Kinematics Model}

This model generates the contact force (longitudinal and lateral forces and aligning torque) at the tyre/road interface. The forces and torques are modeled by the Pacejka formulae for combined slip. This model computes the location and velocity of the tire/road contact point (called B) from the wheel centre (called A). The goal of this is to be able to increase the complexity of the model using either the signal library or the 1D mechanical library i.e. look-up tables or equations for vertical comfort analysis.

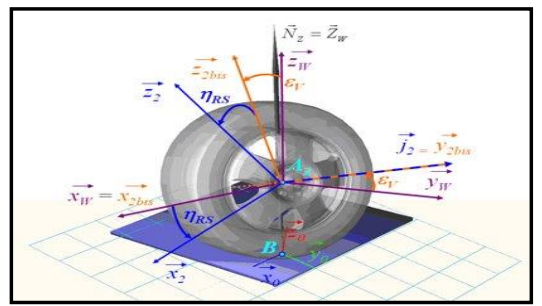

Figure 3: Tire Kinematics Module

\subsubsection{Contact Area or Belt Model}

This model computes all the slip quantities that will be used in the tire model. The model uses the relaxation length technique, the longitudinal slip and side slip stiffness combined with the longitudinal and lateral stiffness to calculate the relaxation lengths. This model handles the steering torque in car park maneuvers.

The characteristic quantities (the slips which are outputs of the model) are detailed below:

- Side slip \& Turn Slip angle in degree

- Longitudinal slip.

- Camber angle (wheel/road) in degree

- Vertical load of the tire in Newton

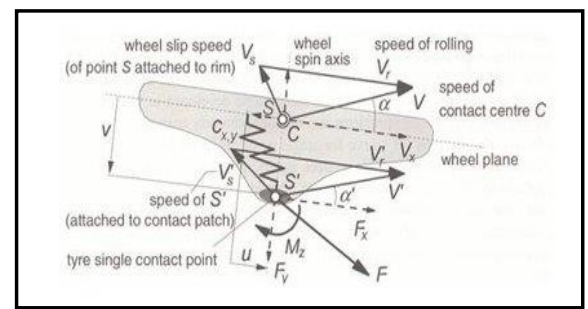

Figure 4: Contact Area Belt Model

\subsubsection{Road Model}

The road model gives access to all the ground inputs; the height, the velocity, the ground normal vector and a constant adherence that equals 1 . This normal vector is essential since it will lead to the calculation of the tire frame. In this study a simple flat road is considered for analysis.

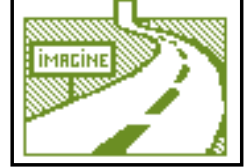

Figure 5: Road Model 


\subsubsection{Adherence Model}

The adherence given to the tire model is a modulation of the signal input given by the user. This makes it possible to pilot the adherence by external means but may use the tire/road contact point. The adherence given by the user is multiplied by a modulation coefficient called "tire characterization reference adherence". This parameter of the sub-model refers to the adherence coefficient at which the tires models are defined. In this study the adherence coefficient is taken as one.

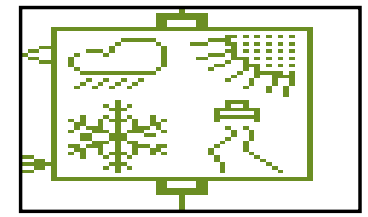

Figure 6: Adherence Model

\subsubsection{Tire Model}

A widely used semi-empirical tire model to calculate steady-state tire force and moment characteristics for use in vehicle dynamics studies is based on the so called Magic Formula. This tire model was developed by $\mathrm{H}$. Pacejka of the Delft University of Technology. Tire models compute the longitudinal and lateral forces as well as the $\mathrm{X}, \mathrm{Y}$ and $\mathrm{Z}$ torques from the vertical load and slip coefficients

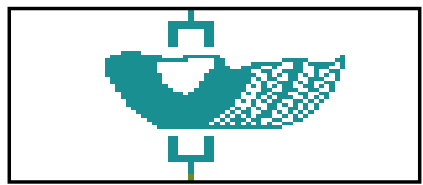

Figure 7: Tire Model

\subsubsection{Suspension Module}

The vehicle considered in this study has Macpherson strut in the front and twist beam assembly rear.The damper curve are used in damper model.Suspension model is connected to chassis via dynamic mechanical node which calculates the summation of all the forces from the suspension.

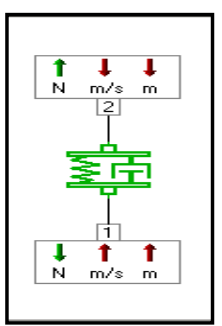

Figure 8: Suspension Module

\subsubsection{Steering Module}

The steering system module needs the following set of parameters

- Stiffness of the whole steering column

- Damper rating of the whole steering column

- Radius of the pinion.

Inputs for assistance table are the steering torque in $\mathrm{Nm}$ and the vehicle speed in $\mathrm{km} / \mathrm{hr}$ which comes from the iCAR sensor subsystem. In case of EPAS, the output is the motor current in 
amperes. The electric motor model is very simple because it consists of a gain modeling the torque constant and inertia. The motor is always linked to a speed reducer called worm gear mechanism. Its main parameters are the gear ratio, the diameters of the gears and the friction coefficients.

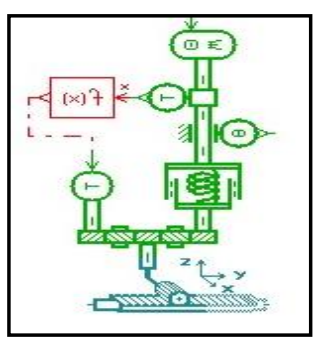

Figure 9: Steering Module

\subsection{Electronic Power Assist Steering System}

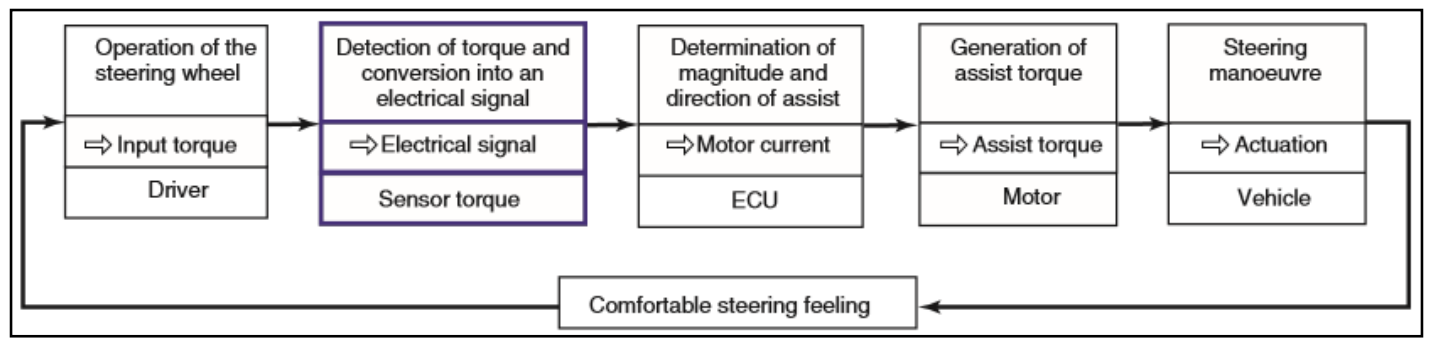

Figure 10: Workflow of an Electronic Power Assist System

${ }^{[1]}$ The driver applies a manual steering torque to the steering wheel. It is detected by a torque sensor and is transmitted as an analog or digital signal to the electronic control unit (ECU) of the steering system. The ECU calculates the necessary assist torque, considering the driving situation. The ECU controls the electric motor correspondingly via the power electronics.

The steering torque accumulated from the manual torque and assist torque is converted into an actuation force by a pinion on the steering rack and transmitted to the wheel unit via the tie rod.

Electric power motor fits on the steering column and it is a brushless DC motor driving the steering column.ECU decides the amount of the power the motor should transfer to the steering column. Torque Sensor mounted on steering column helps in measuring the amount of torque given by the driver.

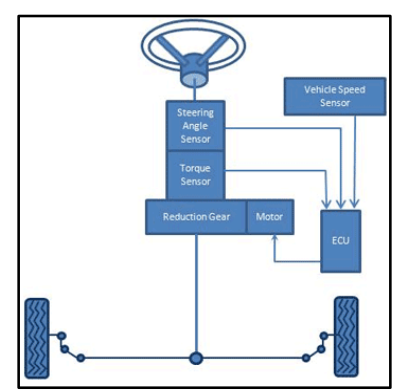

Figure 11: Layout of an EPAS System

ECU takes torque applied by the driver, steering wheel angle, steering wheel speed and the vehicle speed as the four major inputs. The upper half of the steering column is connected to the worm gear which is in mesh with the teeth of the worm screw which forms the base of the DC electric motor. The electric motor worm screw provides the drive to the column, by turning 
worm gear. Within the periphery of the worm gear having external meshing teeth, there lies a ring gear on it's inner side with internal meshing gear teeth. Three planetary gears are in mesh with the inner teeth of the ring gear on their outer periphery and are in mesh with a sun gear on their inner periphery. There lies a carrier which connects the 3 planetary gears with the lower half shaft of the steering column, which in-turn drives the pinion gear turning over the rack.

During the normal EPAS operation the power from the ring gear is directly transferred to the carrier connected to the pinion gear shaft. During the failure of the motor, the worm screw cannot drive the worm gears. Hence incase of failure, when the steering wheel is turned, it rotates the sun gear which in-turn drives the planet gears within the ring gear, thereby turning the carrier connected to the pinion gear shaft.

\subsection{Vehicle Dynamics-Steady State Cornering}

${ }^{[2]}$ The term handling implies to the responsiveness of the vehicle to driver's input. It is the overall measure of the vehicle driver combination. The driver analyses the vehicle direction \& corrects his/her responsive input to achieve the desired motion.

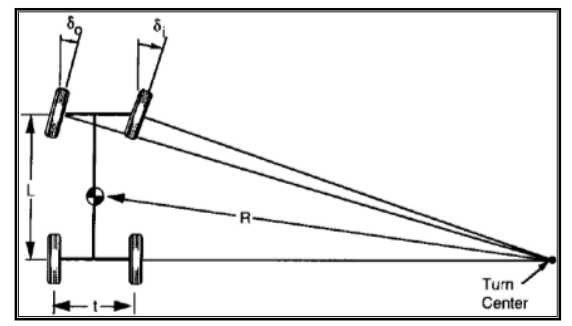

Figure 12: Ackerman's Principle Diagram

The term under-steer gradient is a measure of vehicle's performance under steady state conditions. The cornering approach analyzes the turning behavior firstly at low speed \& then considers the differences arising under high speed conditions. At low speed/ parking lot maneuvers the tires need not develop lateral forces, thus they roll with no slip angles. If the rear wheels have no slip angles the center of the turn lies on the projection of the rear axle. The perpendiculars from the centers of each of the front wheels must pass through the same point to fulfill the Ackerman's Principle. With the correct Ackerman Geometry, the steering torques tend to increase consistently with the increasing steer angles, thus providing the driver with a natural feel in the feedback through the steering wheel.

$\delta_{\circ} \cong L /\left[R+\frac{t}{2}\right]$
$\delta_{i} \cong L /\left[R-\frac{t}{2}\right]$

\subsubsection{Cornering Equation}

${ }^{[2]}$ At higher cornering speeds, the tires develop lateral forces to counteract the lateral acceleration \& slip angles present at each wheel. Under cornering conditions the tyre develops a lateral force, while experiencing lateral slip during the roll. The angle between the direction of travel and direction of heading is known as the slip angle, denoted by term " $\alpha$ ". The lateral force Fy is given by the following equation. The proportionality constant is known as the cornering stiffness coefficient.

$\mathrm{F}_{\mathrm{y}}=\mathrm{C}_{\alpha} \alpha$ 
For the purpose of deriving the cornering equations, we represent the vehicle by a bicycle model in which the front \& rear two wheels can be represented by one wheel each respectively, at a steer angle $\delta$, with a cornering force equivalent to both wheels. For a vehicle travelling forward with a speed of $\mathrm{V}$, the summation of the forces in lateral direction from the tires must equal the mass times the centripetal acceleration, as given in the equation below.

$\Sigma \mathrm{F}_{\mathrm{y}}=\mathrm{F}_{\mathrm{yf}}+\mathrm{F}_{\mathrm{yr}}=\mathrm{MV}^{2} / \mathrm{R}$

- $\mathrm{F}_{\mathrm{yf}}=$ Lateral(cornering) force at the front axle

- $\mathrm{F}_{\mathrm{yr}}=$ Lateral (cornering) force at the rear axle

- $\mathrm{M}=$ Mass of the vehicle

- $\mathrm{V}=$ Forward velocity

- $\mathrm{R}=$ Radius of the turn

Referring the Bicycle Model diagram as shown above, for the vehicle to be in moment equilibrium about the center of gravity, the summation of the moments from the front \& rear lateral forces must be zero.

$\mathrm{F}_{\mathrm{yf}} \mathrm{b}-\mathrm{F}_{\mathrm{yr}} \mathrm{c}=0$

$\Sigma \mathrm{F}_{\mathrm{y}}=\mathrm{F}_{\mathrm{yf}}+\mathrm{F}_{\mathrm{yr}}=\mathrm{MV}^{2} / \mathrm{R}$

Solving for both the above equations we can derive the equations for Lateral force at the front \& rear wheels:

$\mathrm{F}_{\mathrm{yf}}=\mathrm{Mc} / \mathrm{L}\left[\frac{\mathrm{V}^{2}}{\mathrm{R}}\right]$

$\mathrm{F}_{\mathrm{yr}}=\mathrm{Mb} / \mathrm{L}\left[\frac{\mathrm{V}^{2}}{\mathrm{R}}\right]$

- The term $\mathrm{Mb} / \mathrm{L}=\mathrm{Wr} / \mathrm{g}=$ the portion of the mass carried by the rear axle.

- The term $\mathrm{Mc} / \mathrm{L}=\mathrm{W}_{\mathrm{f}} / \mathrm{g}=$ the portion of the mass carried by the front axle.

- The slip angles at the front are represented as:

$\mathrm{a}_{\mathrm{f}}=\mathrm{W}_{\mathrm{f}} \mathrm{V}^{2} / \mathrm{gRC}_{\alpha \mathrm{f}}$

$\mathrm{a}_{\mathrm{r}}=\mathrm{W}_{\mathrm{r}} \mathrm{V}^{2} / \mathrm{gRC}_{\alpha \mathrm{r}}$

$\delta=\frac{57.3 \mathrm{~L}}{\mathrm{R}}+\alpha_{\mathrm{f}}-\alpha_{\mathrm{r}}$

$\delta=\frac{57.3 \mathrm{~L}}{\mathrm{R}}+\left[\frac{\mathrm{W}_{\mathrm{f}}}{\mathrm{C}_{\alpha \mathrm{f}}}-\frac{\mathrm{W}_{\mathrm{r}}}{\mathrm{C}_{\alpha \mathrm{r}}}\right] \mathrm{V}^{2} / \mathrm{gR}$

- $\delta=$ Steer angle at the front wheels

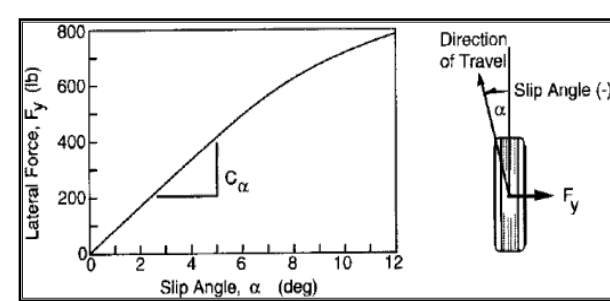

Figure 13: Plot of Slip Angle vs.

- $\mathrm{L}=$ Wheelbase

- $\mathrm{R}=$ Radius of turn

- $\mathrm{V}=$ Forward Speed

- $\mathrm{g}=$ Gravitational acceleration constant

- $\mathrm{W}_{\mathrm{f}}=\mathrm{Load}$ on the front axle

- $\mathrm{W}_{\mathrm{r}}=\mathrm{Load}$ on the rear axle

- $\mathrm{C}_{\alpha \mathrm{f}}=$ Cornering stiffness of the front tires

- $\mathrm{C}_{\alpha \mathrm{r}}=$ Cornering stiffness of the rear tires

\subsubsection{Under-steer Gradient}

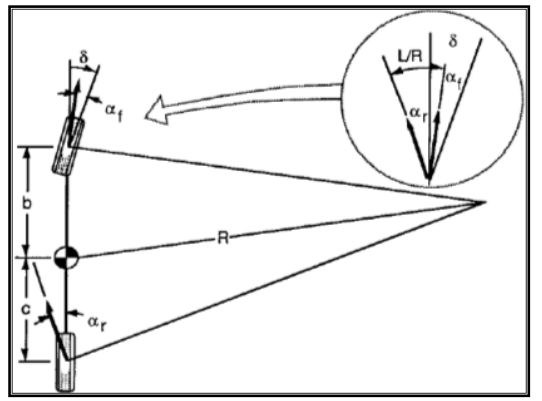

Figure 14: Bicycle Model in Vehicle Dynamics

${ }^{[2]}$ The equation of understeer gradient is very important in analysis of the turning response properties of the motor vehicle. 
$\delta=\frac{57.3 L}{R}+K a_{y}$

$\mathrm{K}=\left[\frac{\mathrm{W}_{\mathrm{f}}}{\mathrm{C}_{\mathrm{af}}}-\frac{\mathrm{W}_{\mathrm{r}}}{\mathrm{C}_{\mathrm{ar}}}\right]=$ Under-steer gradient $[\mathrm{deg} / \mathrm{g}]$

It is the ratio of load on the axle to the cornering stiffness of the tire.

$a_{y}=\mathrm{V}^{2} / \mathrm{gR}=$ Lateral acceleration $[\mathrm{g}]$

It describes how the steering angle of the vehicle must be changed with respect to the turning radius $R$. The term under-steer gradient determines the magnitude \& direction of the steering input required. The three different possibilities under Under-steer gradient are:

\subsubsection{Case I: Neutral-steer}

${ }^{[2]}$ Neutral steer is a case corresponding to the balance on the vehicle such that the lateral force at CG causes an identical increase in slip angle at both the front\& rear wheels. Hence during a constant radius turn, the steer angle required to make the turn will be equivalent to Ackerman angle.

$\frac{\mathrm{W}_{\mathrm{f}}}{\mathrm{C}_{\alpha \mathrm{f}}}=\frac{\mathrm{W}_{\mathrm{r}}}{\mathrm{C}_{\alpha \mathrm{r}}} \rightarrow \mathrm{K}=0 \rightarrow \alpha_{\mathrm{f}}=\alpha_{\mathrm{r}}$

\subsubsection{Case II: Under-steer}

${ }^{[2]}$ In this case, during a constant radius turn, the steer angle is increased linearly with the vehicle speed, in proportion to $\mathrm{K}$ times the lateral acceleration in ' $\mathrm{g}$ '.

Lateral acceleration at CG causes the front wheels to slip sideways to a greater extent compared to the rear axle.

Thus to develop the lateral force at the front wheels necessary to maintain the radius of turn, the front wheels have to be steered at higher value of angles.

$\frac{W_{\mathrm{f}}}{\mathrm{C}_{\alpha \mathrm{f}}}>\frac{\mathrm{W}_{\mathrm{r}}}{\mathrm{C}_{\alpha \mathrm{r}}} \rightarrow \mathrm{K}>0 \rightarrow \alpha_{\mathrm{f}}>\alpha_{\mathrm{r}}$

\subsubsection{Case III: Over-steer}

${ }^{[2]}$ In this case, during a constant radius turn, the steering angle is decreased with the increasing speed \& lateral acceleration.

The lateral acceleration at the CG causes the slip angle on the rear wheels to increase compared to that of the front wheels.

The outward drift at the rear of the vehicle turns the front wheels inwards, thus diminishing the turning radius.

The process continues till the steering wheel angle is reduced to maintain the radius of the turn.

$\frac{\mathrm{W}_{\mathrm{f}}}{\mathrm{C}_{\alpha \mathrm{f}}}<\frac{\mathrm{W}_{\mathrm{r}}}{\mathrm{C}_{\alpha \mathrm{r}}} \rightarrow \mathrm{K}<0 \rightarrow \alpha_{\mathrm{f}}<\alpha_{\mathrm{r}}$

\subsubsection{Sideslip Angle}

${ }^{[2]}$ During cornering at low speed when the lateral acceleration is negligible, the rear wheel tracks are inboard of the front wheels.But as the lateral acceleration increases the rear of the vehicle must drift outboard to develop the necessary slip angle on the rear tires. At any point on the vehicle sideslip may be defined as the angle between the longitudinal axis and the local direction 
of travel. The value of sideslip angle is different in intensity at every single point on a car during cornering.

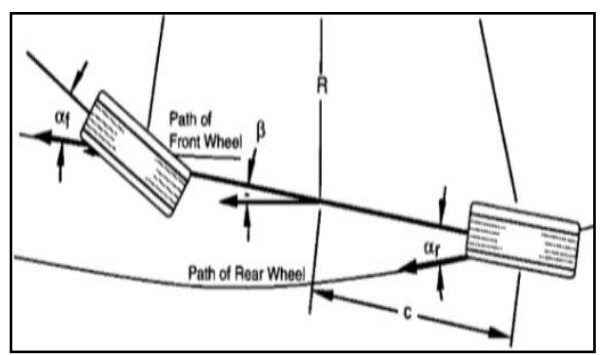

Figure 15: Variation of Slip Angle during Cornering

\section{Problem definition}

\subsection{Phase1}

- Steering System Model Development

- Full vehicle model development along with integrated steering \& conventional power train.

- Digital assessment of steering PAT targets.

\subsection{Phase 2}

- Replacement of conventional power-train with EV power-train.

- Digital assessment of steering PAT targets \& it's comparison with conventional power train [Impact Measurement].

- Propose design modifications to improve the steering performance on vehicle with EV power train.

\subsection{Phase 3}

- Perform phase $1 \& 2$ activities for all the three vehicle models.

\subsection{Objectives}

- Full vehicle model development using AMESim platform with a complete focus on the Steering System Module.

- Generation of kinematic and compliance files by implementing various vehicle, geometrical, kinematic \& CG parameters in the $\mathrm{KnC}$ application.

- Conduct the complete simulation of the AMESim model by implementing the $\mathrm{KnC}$ files along with the mass inertia and tire properties into the model.

- Steering PAT target assessment with conventional powertrain.

- Steering PAT target assessment with replacement of conventional powertrain with EV powertrain.

- Comparison of the results and proposal of design modifications to improve the steering performance on vehicle with EV powertrain. 


\section{Methods of analysis}

\subsection{Modeling Methodology in AMESim}

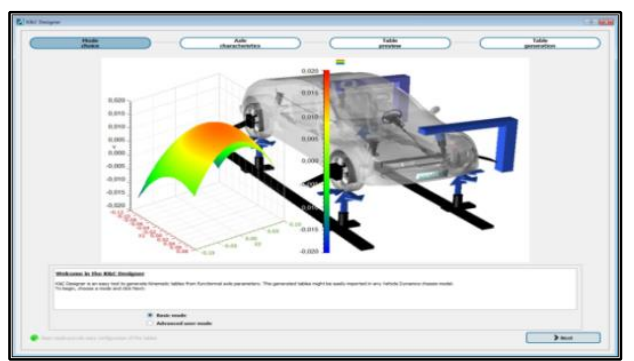

Figure 16: AMESim KnC Application

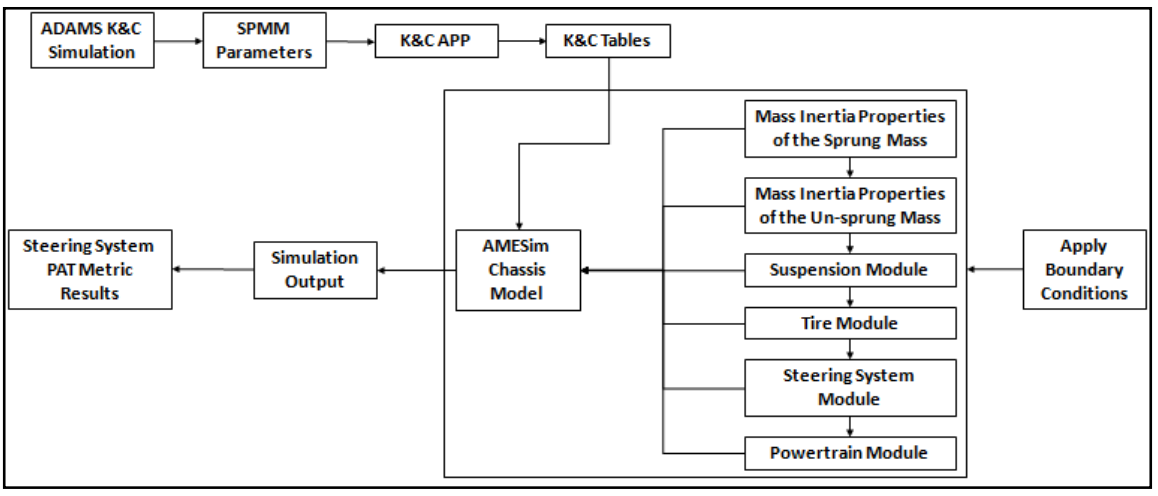

Figure 17: Modeling Methodology in AMESim

Modeling in AMESim Platform, consist of modeling of various subsystems such as Steering Module, Suspension Module, Sensors Module, Tire Module etc and integrating it all together with the Chassis Module to form a Full Vehicle Model.SPMM parameters are calculated from SVC and DAP files, [obtained from ADAMS simulation] to generate a list of required parameters needed for the simulation of Steering System Module.Uploading of the SPMM parameters into the Kinematics \& Compliance application of AMESim Model is done to generate $20 \mathrm{KnC}$ tables.

Kinematic tables are the "functional representation" forthe definition of axle system geometry. They describe the variation of track width, wheelbase, steering angle, camber angle and self rotating angle as a function of vertical wheel lifts (current and opposite wheel), which facilitates the definition of interdependence of the left and right suspensions and steering rack displacement for front axle system.

Next step involves the uploading of $\mathrm{KnC}$ tables, Tire and Mass Inertia properties into the AMESim model and running the simulation for Conventional Powertrain.Conventional Powetrain is then replaced with the Electric Powertrain and the simulation is re-run, in a manner as mentioned above.

The list of Performance Aggregate Target [PAT] parameters calculated are:

- Steering Sensitivity and Steering Angle Dead-band

- Torsion Rate

- On Centre Yaw Gain and Yaw Gain Dead-band

- Steering Wheel Torque at specified acceleration values. 
Finally a comparative analysis between the simulation and test results of the Conventional vs. EV model is performed.

\subsubsection{SPMM Parameters}

Table 1: SPMM Parameters

\begin{tabular}{|l|l|l|l|l|l|}
\hline Vehicle Parameters & Unit & $\begin{array}{l}\text { Geometrical } \\
\text { Parameters }\end{array}$ & $\begin{array}{l}\text { Uni } \\
\text { t }\end{array}$ & Kinematic Parameters & Unit \\
\hline Wheelbase & $\mathrm{mm}$ & Front Toe Angle & $\mathrm{deg}$ & Front Bump Steer Coefficient & $\mathrm{deg} / \mathrm{mm}$ \\
\hline Steering Ratio & $\mathrm{deg} / \mathrm{deg}$ & Front Camber Angle & $\mathrm{deg}$ & $\begin{array}{l}\text { Front Bump } \\
\text { Coefficient }\end{array}$ & $\mathrm{damber}$ \\
\hline Pinion Radius & $\mathrm{mm}$ & Front Caster Angle & $\mathrm{deg}$ & Rear Bump Steer Coefficient & $\mathrm{deg} / \mathrm{mm}$ \\
\hline Wheel Radius & $\mathrm{mm}$ & Front Caster Offset & $\mathrm{mm}$ & Rear Roll Steer Coefficient & $\mathrm{deg} / \mathrm{mm}$ \\
\hline Front Track & $\mathrm{mm}$ & Front Kingpin Angle & $\mathrm{deg}$ & Rear Bump Camber Coefficient & $\mathrm{deg} / \mathrm{mm}$ \\
\hline Front Roll Centre Height & $\mathrm{mm}$ & Front Kingpin Offset & $\mathrm{mm}$ & Rear Roll Camber Coefficient & deg/mm \\
\hline Rear Track & $\mathrm{mm}$ & Rear Toe Angle & $\mathrm{deg}$ & & \\
\hline Rear Roll Centre Height & $\mathrm{mm}$ & Rear Camber Angle & $\mathrm{deg}$ & & \\
\hline
\end{tabular}

\subsubsection{Kinematic and Compliance Tables}

Table 2: List of Kinematics \& Compliance Tables

\begin{tabular}{|l|l|l|l|l|}
\hline & Front Left & Front Right & Rear Left & Rear Right \\
\hline Wheel Recession & Xa11 & Xa12 & Xa21 & Xa22 \\
\hline Track Change & Ya11 & Ya12 & Ya21 & Ya22 \\
\hline Steer & Delta11 & Delta12 & Delta21 & Delta22 \\
\hline Camber & Epsillon11 & Epsillon12 & Epsillon21 & Epsillon22 \\
\hline Spin & Eta11 & Eta12 & Eta21 & Eta22 \\
\hline
\end{tabular}

\subsubsection{Mass Inertia \& CG Parameters}

Table 3: Mass Inertia \& CG Parameters

\begin{tabular}{|c|c|c|c|c|}
\hline Mass Inertia Properties & Units & Mass Inertia Properties & & Units \\
\hline Sprung Mass & $\mathrm{kg}$ & Sprung Mass Inertia & Ixx & $\mathrm{kg}-\mathrm{m}^{2}$ \\
\hline Total Mass & $\mathrm{kg}$ & & Iyy & $\mathrm{kg}-\mathrm{m}^{2}$ \\
\hline Front Sprung Mass & $\mathrm{kg}$ & & Izz & $\mathrm{kg}-\mathrm{m}^{2}$ \\
\hline Rear Sprung Mass & $\mathrm{kg}$ & & Ixy & $\mathrm{kg}-\mathrm{m}^{2}$ \\
\hline Front Spindle Mass & $\mathrm{kg}$ & & Iyz & $\mathrm{kg}-\mathrm{m}^{2}$ \\
\hline Rear Spindle Mass & $\mathrm{kg}$ & & Izx & $\mathrm{kg}-\mathrm{m}^{2}$ \\
\hline Front Wheel Mass & $\mathrm{kg}$ & Wheel Inertia & Ixx & $\mathrm{kg}-\mathrm{m}^{2}$ \\
\hline \multirow[t]{2}{*}{ Rear Wheel Mass } & $\mathrm{kg}$ & & Iyy & $\mathrm{kg}-\mathrm{m}^{2}$ \\
\hline & & & Izz & $\mathrm{kg}-\mathrm{m}^{2}$ \\
\hline \multicolumn{2}{|l|}{ CG Computed } & & & \\
\hline ECIE_x & $\mathrm{mm}$ & & & \\
\hline ECIE_y & $\mathrm{mm}$ & & & \\
\hline ECIE_z & $\mathrm{mm}$ & & & \\
\hline
\end{tabular}

\section{Results and discussion}

\subsection{Boundary Conditions}

- Sinusoidal steering input is applied to the vehicle at $100 \mathrm{~km} / \mathrm{hr}$ on a straight road. 
- The steering wheel angle is increased till the lateral acceleration achieved is between $0.4 \mathrm{~g}$ $0.5 \mathrm{~g}$.

- The corresponding steering wheel angle measured is 35 degrees.

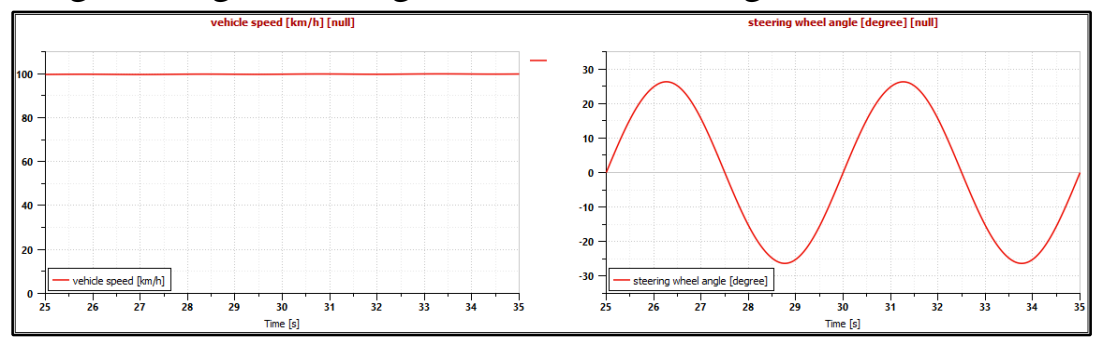

Figure 16: Boundary Conditions

\subsection{Performance Aggregate Target Parameters}

\subsubsection{Steering Sensitivity $[\mathrm{g} / 100 \mathrm{degSWA}]$}

The variation in lateral acceleration on a level road with respect to change in steering wheel angle at a given test condition is known as the Steering Sensitivity. It has a progressive effect on how much the tires will turn in, based on the input. The higher the sensitivity, the more the wheel will turn during first degrees of steering wheel. With lower sensitivity, the first degrees of steering will have a lesser turning effect on road wheels. This signifies how fast the vehicle's lateral acceleration varies with time.

\subsubsection{Steering Wheel Torque $[\mathrm{Nm}]$}

Steering Wheel Torque is the torque applied on the steering wheel by the driver.Steering wheel torque at $0 \mathrm{~g}$ signifies the friction in the steering system\& the torque at $0.3 \mathrm{~g}$ is the measure of steering effort.

\subsubsection{Torsion Rate $[\mathrm{Nm} / 100 \mathrm{deg} \mathrm{SWA}]$}

Torsion Rate is defined as change in steering wheel torque with respect to change in steering wheel angle.It assists the driver in judging the stiffness level of the steering and analyzes the appropriate intensity of the torque required to turn the steering wheel.

\subsubsection{Steering Angle Dead band [deg]}

Steering Wheel Angle Dead-bandis calculated at '0'g lateral acceleration. It is described as the phase wherein, any change in the position of Steering Wheel, brings about no observable response in the position of road wheels. It clearly states as to how much steering wheel angle is necessary to get a vehicle response in lateral acceleration.

\subsubsection{On Centre Yaw Gain [deg/sec/100 degSWA]}

Yaw is simply an indication of a vehicle's rotation about it's vertical axis. On Centre Yaw Gain is the variation in the yaw rate with respect to change in steering wheel angle. It signifies tendency of the vehicle to deviate from the vertical axis with variation in steering wheel angle. 


\subsubsection{Yaw Gain Dead band [deg]}

Yaw Gain Dead-band is defined as the delay in the variation of yaw gain for a particular phase of changing steering wheel angle. Vehicle turning get affected due to this dead-band. It signifies as to how much steering wheel angle is necessary to obtain a yaw gain.

\subsection{Simulation Results}

\subsubsection{Steering Wheel Angle vs. Lateral Acceleration_Vehicle Model 1}

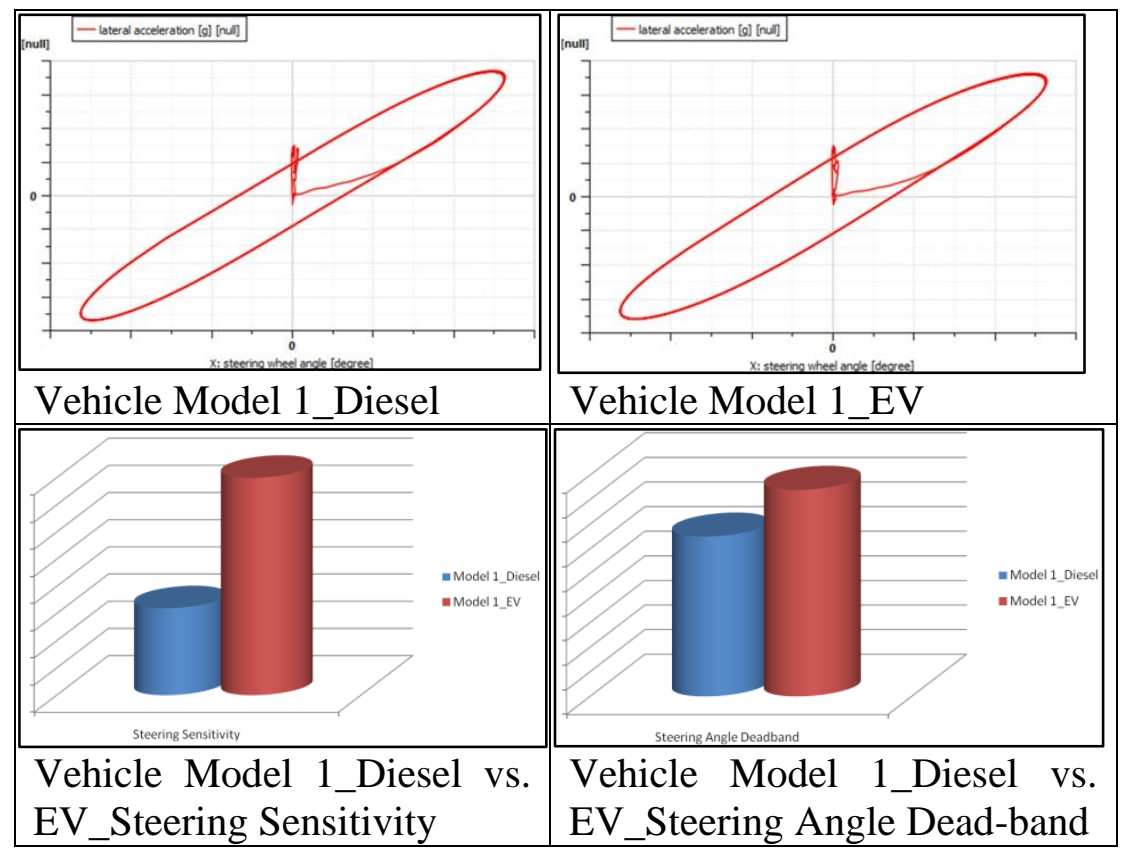

5.3.2. Steering Wheel Angle vs. Lateral Acceleration_Vehicle Model 2
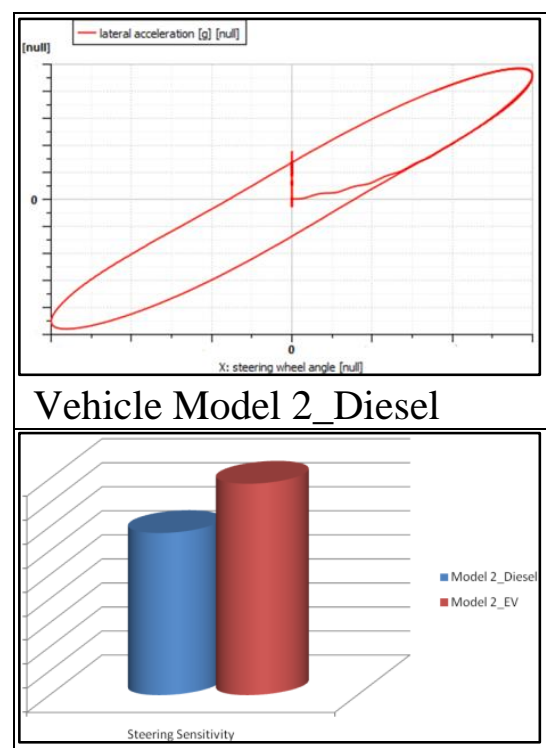

Vehicle Model 2_Diesel vs. EV_Steering Sensitivity

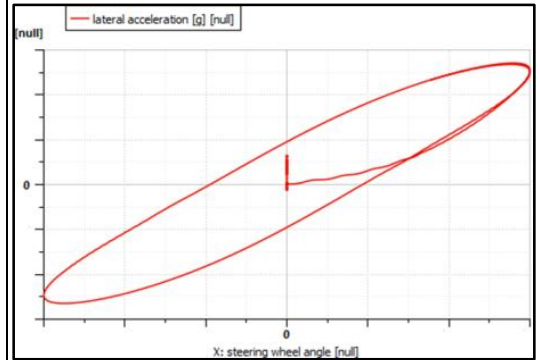

Vehicle Model 2_EV

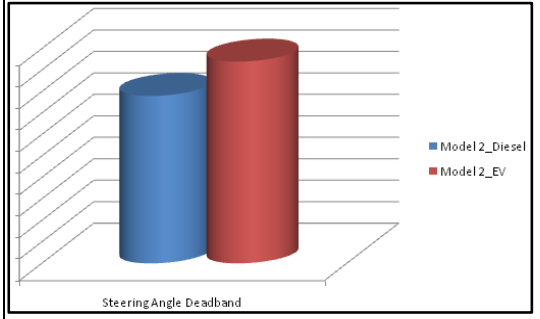

Vehicle Model 2_Diesel vs. EV_Steering Angle Dead-band 


\subsubsection{Steering Wheel Angle vs. Lateral Acceleration_Vehicle Model 3}

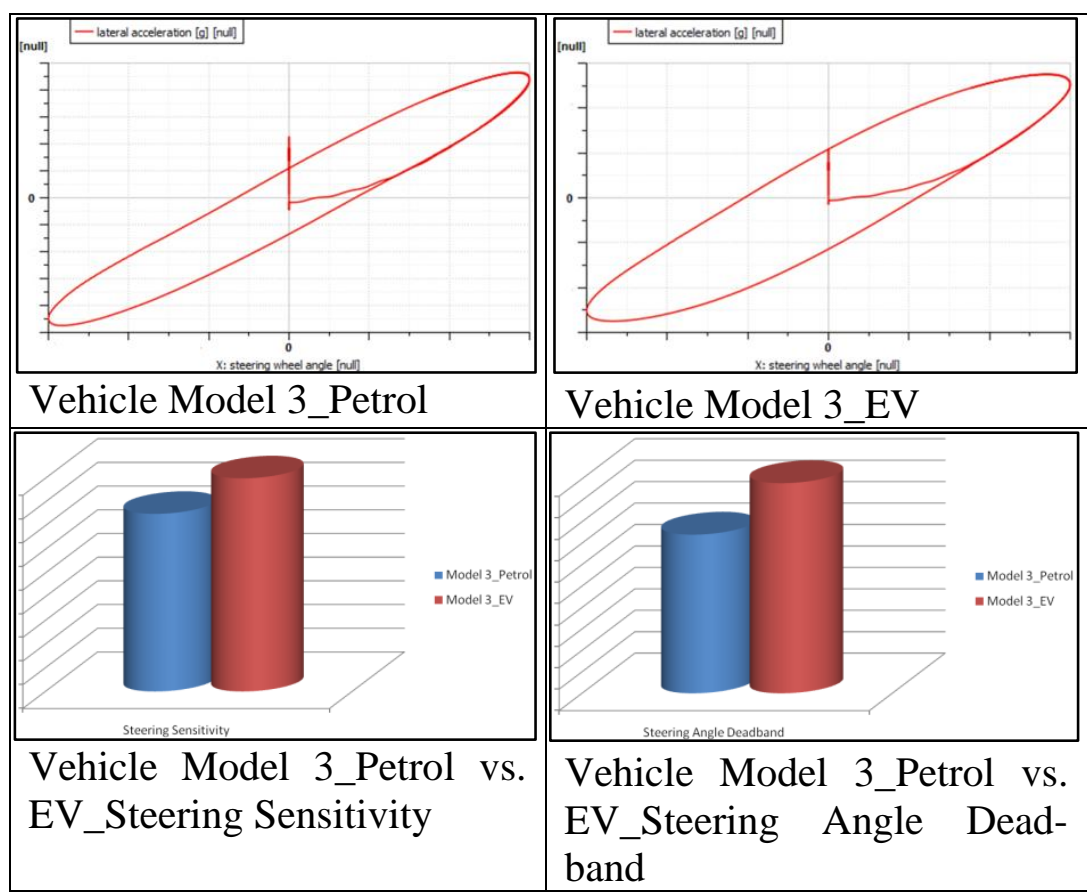

5.3.4. Steering Wheel Angle vs. Steering Wheel Torque_Vehicle Model 1
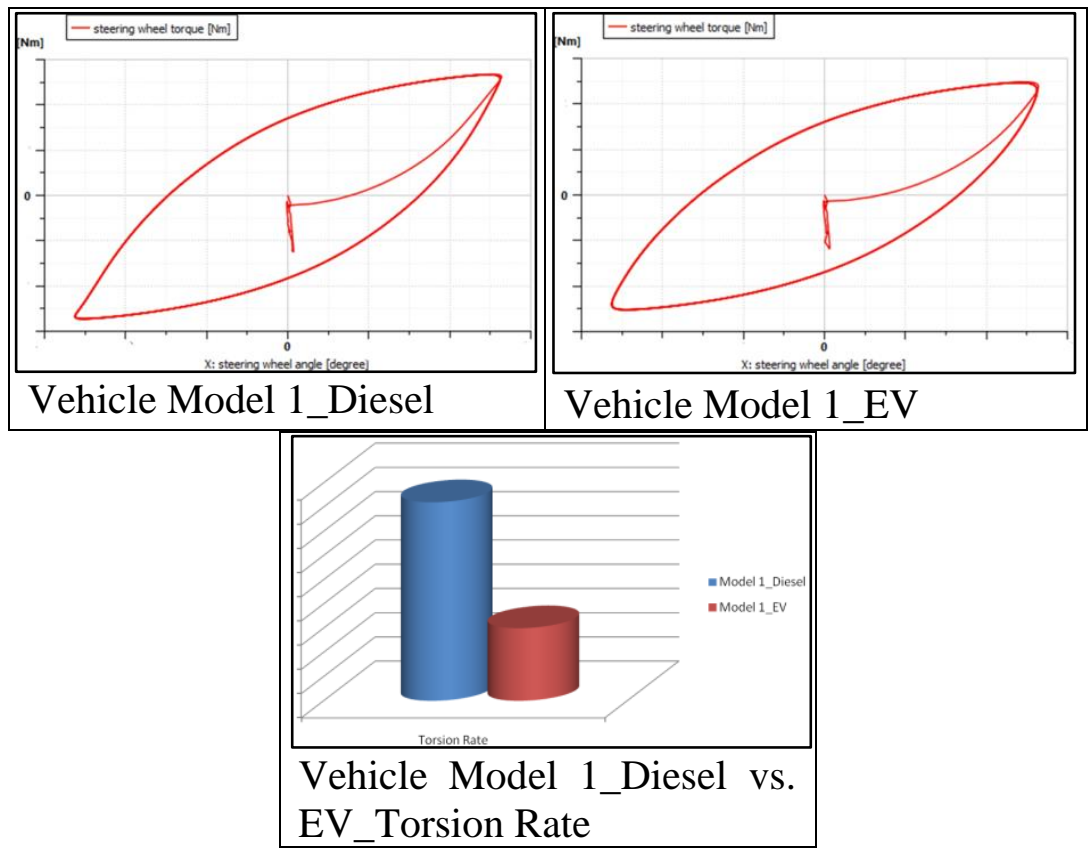


\subsubsection{Steering Wheel Angle vs. Steering Wheel Torque_Vehicle Model 2}

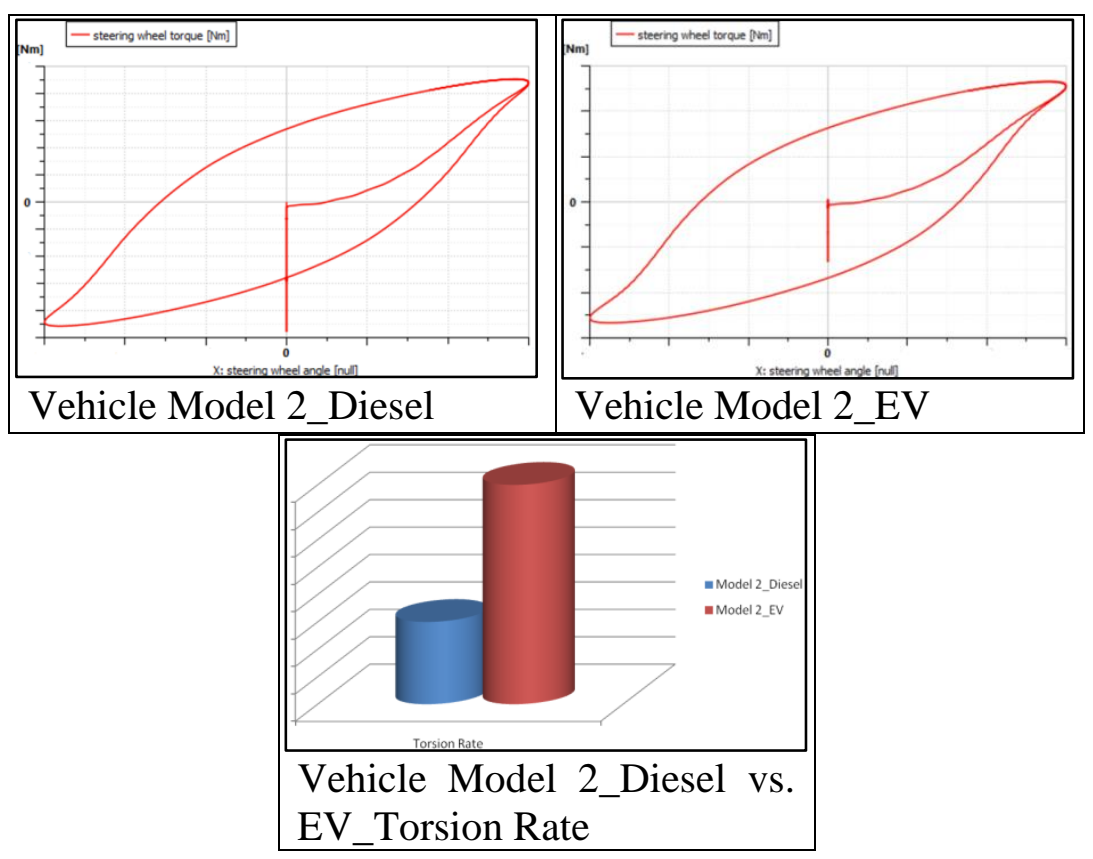

5.3.6. Steering Wheel Angle vs. Steering Wheel Torque_Vehicle Model 3

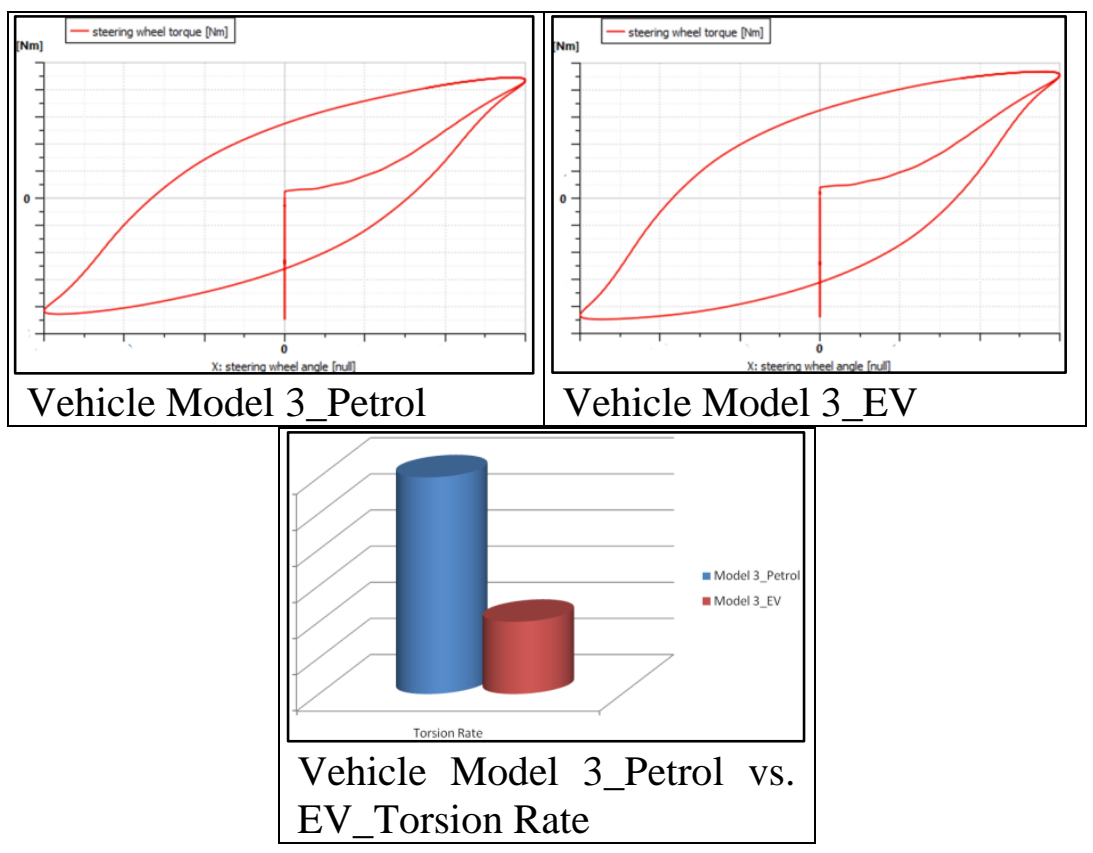




\subsubsection{Steering Wheel Angle vs. Yaw Rate_Vehicle Model 1}

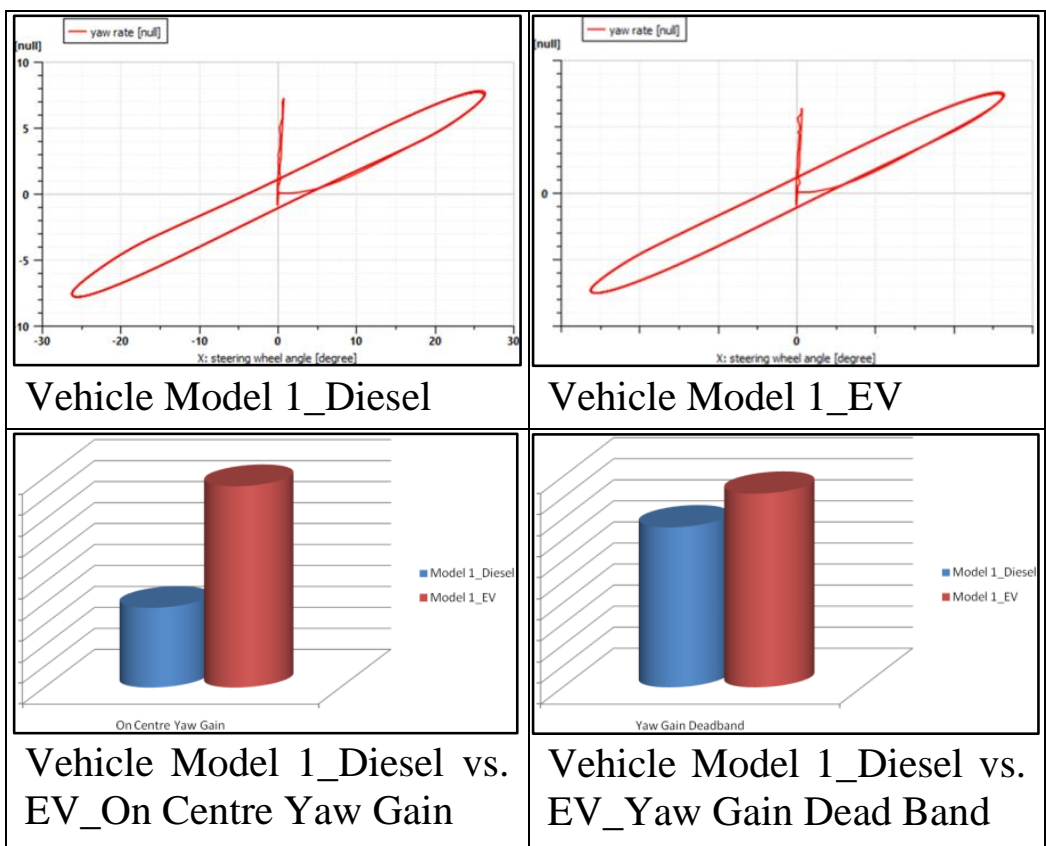

5.3.8. Steering Wheel Angle vs. Yaw Rate_Vehicle Model 2
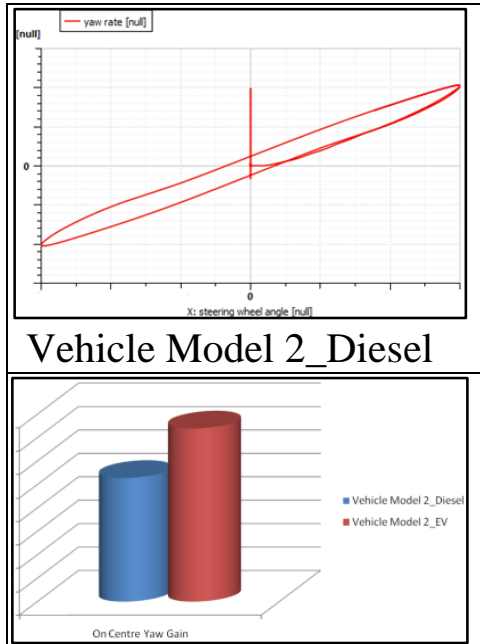

Vehicle Model 2_Diesel vs. EV_On Centre Yaw Gain

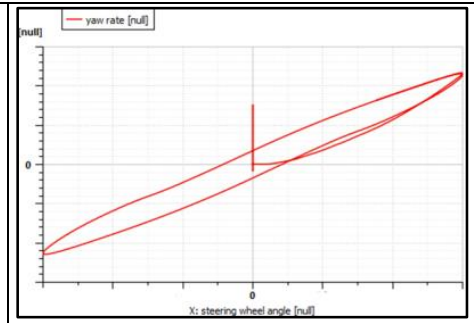

Vehicle Model 2_EV

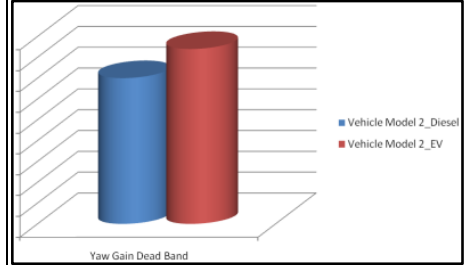

Vehicle Model 2_Diesel vs. EV_Yaw Gain Deadband 
5.3.9. Steering Wheel Angle vs. Yaw Rate_Vehicle Model 3
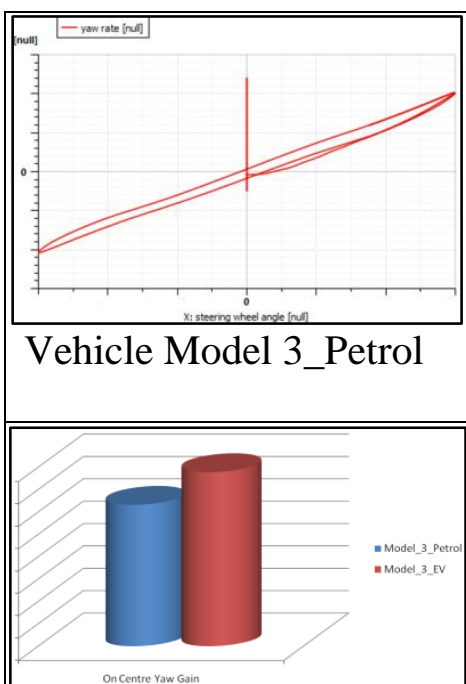

Vehicle Model_3_Petrol vs. EV_On Centre Yaw Gain

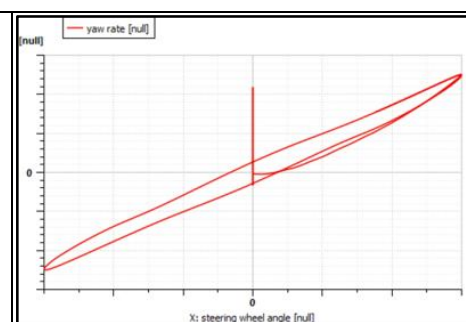

Vehicle Model 3_EV

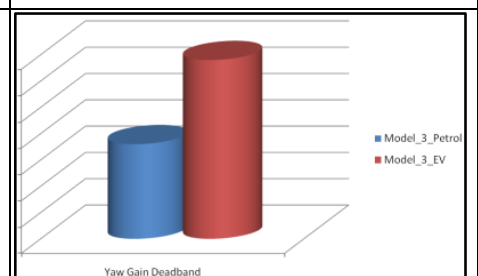

Vehicle Model_3_Petrol vs. EV_Yaw Gain Deadband

5.3.10. Lateral Acceleration vs. Steering Wheel Torque_Vehicle Model 1

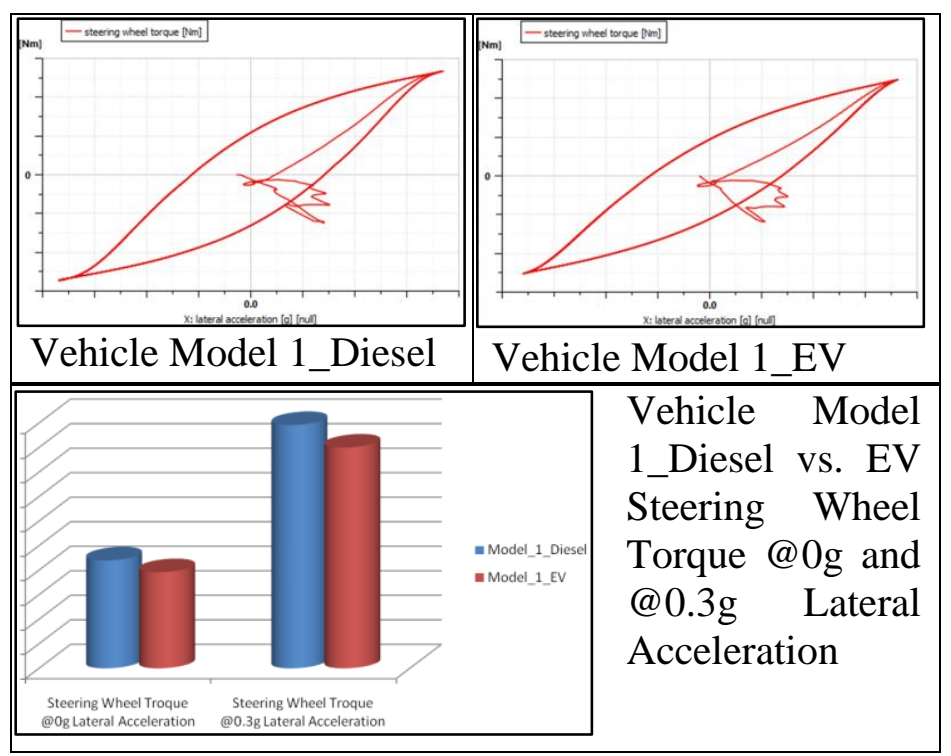




\subsubsection{Lateral Acceleration vs. Steering Wheel Torque_Vehicle Model 2}

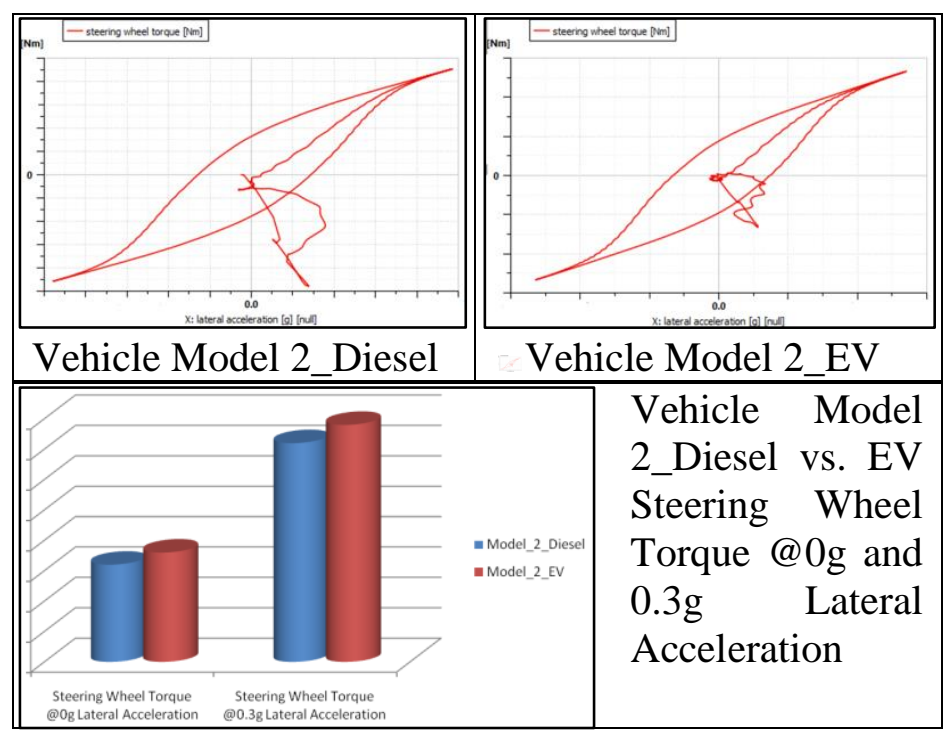

5.3.12. Lateral Acceleration vs. Steering Wheel Torque_Vehicle Model 3

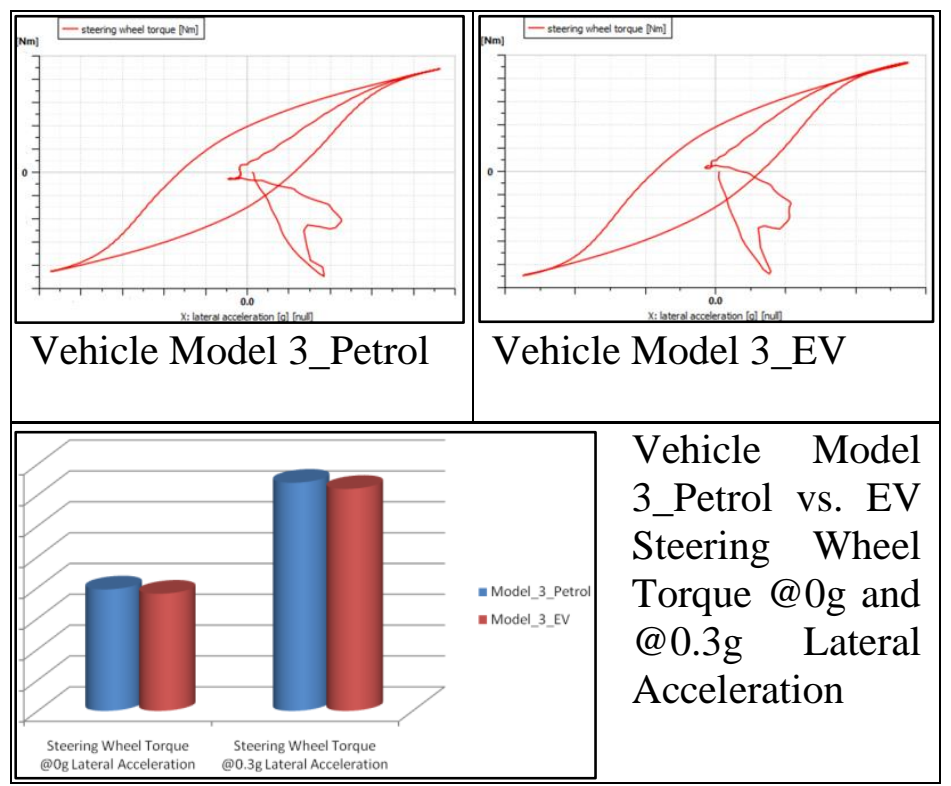

\section{Conclusion}

\subsection{Observation on Steering Sensitivity and Steering Angle Dead band}

6.1.1. Steering sensitivity of the electric variant is higher as compared to its conventional variant, as observed in all the three vehicle models.

Justification: Since the rear axle weight of the conventional variant is higher, hence the CG of the vehicle lies closer to the rear axle. By applying the principle of Bicycle Model from Vehicle Dynamics, we observe that, during cornering higher lateral forces are produced at the rear axle wheels causing higher slip angles at the rear. This in-turn reduces the under-steer gradient \& 
helps the vehicle to maintain same curve radius, even at higher speeds with lower steering angles. Hence the steering sensitivity of the electrical variant is higher as compared to it's conventional variant.

6.1.2. Steering angle dead-band in the electric variant is higher as compared to it's conventional variant.

Justification: A dead-band is a region wherein, even though the steering wheel is being steered, no inputs are being recorded at the road wheels, so the vehicle continues on its recommended path. A vehicle with a higher steering sensitivity is very sensitive for changes in steering wheel angle; a small change in steering wheel angle would cause the vehicle to have a relative higher lateral acceleration. Every steering wheel angle will generate different values of lateral acceleration, resulting in different self aligning moments of the tires producing varying frictional forces in the steering system. The increased steering friction at the rack leads to the reduction in steering response; hence it might be one of the factors leading to steering angle dead-band being higher in electric variant.

\subsection{Observation on Torsion Rate}

6.2.1. Torsion rate in conventional variant is observed to be higher as compared to it's electric variant.

Justification:The ECU takes up the following input: Torque applied by the driver, Steering wheel angle, Steering wheel speed \&Vehicle speed\& generates the appropriate steering wheel torque. The quicker torque feedback felt by the driver at the higher speeds restricts the driver from turning the steering wheel excessively. In a similar manner, at lower speeds, the driver needs to make comparatively more efforts to turn the steering wheel for larger steering angles. Since the front axle weight of the conventional variant is higher as compared to it's electrical variant, the slip angles and the lateral forces developed at front wheel contact patch during cornering are higher. Hence the magnitude of the aligning torque generated at front wheel contact patch is also higher. The under-steer gradient for the conventional variant is higher as compared to it's electric variant making the vehicle to turn with higher steering wheel angles. Hence the torsion rate is higher in conventional variant compared to the electric variant.

6.2.2. As an exceptional case, the torsion rate is observed to be lower in the conventional variant of vehicle model 2.

Justification: The ECU after taking the input of steering wheel angle, steering wheel torque, and also the vehicle speed sensor pulses, does a constant comparison between the steering wheel torque calculated and the actual amount of torque required at the rack pinion as per the driving conditions. A cyclic comparison is done by the PID controller unit between the two torque values as mentioned above. Then the appropriate current signal is sent to the assist motor to provide the required assist torque. The assist torque is calculated by looking up the assistance curve table algorithms fed into controller unit. The curve-based assistance characteristics are helpful to realize continuous and uniform assistance and its curve shape can be adjusted according to real requirements. Hence regarding the reduction of the torsion rate in conventional variant of vehicle model 2 , it is the manipulation of the steering assist curves that will help in improving the torsion rate. 


\subsection{Observation on Centre Yaw Gain.}

6.3.1. On centre yaw gain is higher in electric variant as compared to it's conventional variant.

Justification: As observed in all the three vehicle models, the PAT parameter-on centre yaw gain is higher in electrical variant as compared to the conventional variant. As discussed earlier, since the rear axle weight of electric vehicle is higher, hence by applying the principle of "Bicycle Model-Vehicle Dynamics", the reduction in the under-steer gradient occurring, increases the turning rate of the electric vehicle. This makes the electric vehicle to turn at faster rate during a sinusoidal steer test, as compared to it's conventional variant. Yaw rate of the vehicle is majorly affected by the lane change occurring during cornering due to the dynamic load transfer occurring in the lateral direction of the vehicle. This in-turn contributes to the increase in the yaw rate of the electrical variant.

\section{References}

[1] Mathias Wurges/New Electrical Power Steering Systems/Encyclopedia of Automotive Engineering, Online () 2014 John Wiley \& Sons, Ltd./DOI: 10.1002/9781118354179.auto008/Print Edition-ISBN: 978-0-470-97402-5

[2] Thomas .D. Gillespie/Fundamentals of Vehicle Dynamics/Society of Automotive Engineers Inc 1992-02/pp. 79-371

[3] Runqing Guo, Zhaojuan Jiang, Lin Yuan/Application of Steering Robot in the Test of Vehicle Dynamic Characteristics/3rd International Conference on Mechatronics, Robotics and Automation (ICMRA 2015)/@ 2015. The authors - Published by Atlantis Press/pp. 1122-1129

[4] AhnNa Lee, JiHyun Jung, BonGyeong Koo, HangByoung Cha/Steering Assist Torque Control Enhancing Vehicle Stability/The International Federation of Automatic Control/Proceedings of the 17th World Congress,Seoul, Korea/July 6-11, 2008/pp. 5676-5681

[5] R. P. Rajvardhan, S. R. Shankapal, S. M. Vijaykumar/Effect of Wheel Geometry Parameters on Vehicle Steering/SASTECH Journal/Volume 9, Issue 2, September 2010/pp. 11-18

[6] Fuad Un-Noor, Sanjeevikumar Padmanaban, Lucian Mihet-Popa, Mohammad Nurunnabi Mollah, Eklas Hossain/A Comprehensive Study of Key Electric Vehicle (EV)Components, Technologies, Challenges, Impacts, and Future Direction of Development/Energies 2017, 10, 1217/doi:10.3390/en10081217/www.mdpi.com/journal/energies

[7] Liao, Y. Gene and Isaac Du, H. (2003)/Modelling and analysis of electric power steering system and its effect on vehicle dynamic behavior/Int. J. Vehicle Autonomous Systems/Vol. 1, No. 2/pp. 153166.

[8] Vishal N. Sulakhe, Mayur A. Ghodeswar, Meghsham D. Gite/Electric Power Assisted Steering/Int. Journal of Engineering Research and Applications/Vol. 3, Issue 6, Nov-Dec 2013/pp.661-666.

[9] Zhanfeng Gao, Wenjiang Wu, Jianhua Zheng, Zhanpeng Sun/Electric Power Steering System Based on Fuzzy PID Control/@2009 IEEE/The Ninth International Conference on Electronic Measurement \& Instruments, ICEMI'2009/pp. 456-459 